\title{
EDITORIAL
}

\section{A NEW EDITOR FOR THE JOURNAL}

A fter five years of superior service, Dr John Waldhausen has chosen to retire as Editor of our Journal. These have been good years for the Journal.

Associate editors have been added. The time to review and publication has been accelerated, and clinical-pathologic conferences, basic science reviews, editorials, and commentaries have been added to the Journal content. The Journal is now available on the Internet, and its "impact factor," calculated by the Science Citation Index, stands at an enviable 3.068.

Thus, it is with great humility and some trepidation that I assume editorial responsibility for the Journal. Indeed, "online" publishing, new electronic formats, and the enforced delays associated with traditional peer review and paper publishing create conflicting forces in today's market. What will be the role of the Journal in the next five years and how will it evolve? It is safe to say that the ultimate distinguishing feature of the Journal will be its adherence to the peer review process and the critical role that process plays in assuring scientific validity and integrity. I believe the Journal will remain the repository of the most enduring creative works in our specialty and will retain the credibility that encourages us to alter our practice patterns based on the information that is published.

But, the format of the Journal will continue to evolve. We are committed to accelerating the review and publication cycle, and authors will find a level of responsiveness in the editorial office that will please them. We will use more electronic means to facilitate our publication process, including electronic submission, Internet-based reviews, and electronic communication. Authors may suggest a reviewer of their choice, and we will focus heavily on editorials and commentary to help all readers understand the value and role of the work we publish. The arcane world of statistics will be demystified by appropriate commentary that explains many of the assessments used in published articles. Clinical-pathologic conferences will be expanded as a unique educational tool and will cover surgery for adult and congenital cardiac disease, general thoracic surgery, and the areas of perfusion, patient management, and decision making. A section covering emerging technology will be added, as will a section on medical ethics as it pertains to our specialty. We have appointed Martin McKneally, MD, as associate editor for ethics.

As Editor of the Journal, I will assume responsibility for serving as Editor-in-Chief for The American Association for Thoracic Surgery. This will provide the opportunity to

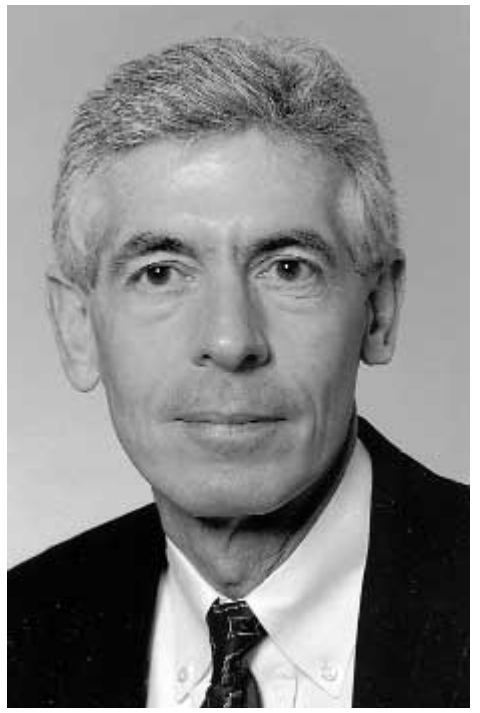
achieve better co-

ordination of all of our educational publications: The Journal of Thoracic and Cardiovascular Surgery, Seminars in Thoracic and Cardiovascular Surgery, Operative Techniques in Thoracic and Cardiovascular Surgery, and the yearly publication, Pediatric Cardiac Surgery Annual. We have a unique opportunity to connect all these publications electronically through appropriate hyperlinking that will enhance the use of the publications of the AATS, including the online-only publication, CTDigest.

So, we have much to do. None of it would be possible without the superb efforts of the associate editors and the members of the Editorial Advisory Board, who will be called on to play an expanded role as the Journal moves forward. The Journal is fortunate to have acquired the services of Ms Pamela Fried as its managing editor. Ms Fried comes to the Journal experienced in every facet of medical journal editing and publishing, including society publishing. Both of us look forward to your comments, suggestions, and submissions and can be reached electronically at JTCVS@drexel.edu. Please let us know how we are doing.

Andrew S. Wechsler, MD

Editor

12/1/106286

doi:10.1067/mtc. 2000.106286 